\title{
Knowledge of and attitudes towards family planning by male teachers in the Islamic Republic of Iran
}

R. Tavakoli ${ }^{1}$ and H. Rashidi-Jahan ${ }^{1}$

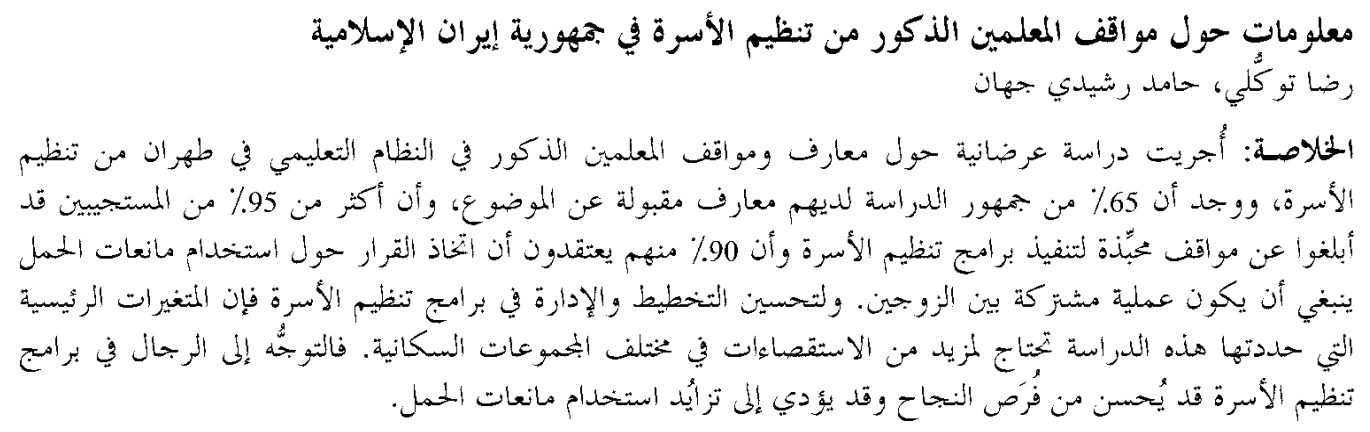

ABSTRACT A cross-sectional study was carried out on knowledge of and attitudes to family planning in male teachers working in the education system in Teheran. We found that $65 \%$ of the study population had acceptable knowledge regarding the issue. More than $95 \%$ of respondents reported having a favourable attitude towards the implementation of family planning programmes and about $90 \%$ believed that decisionmaking regarding use of contraceptives should be a joint process. To improve the planning and administration of family planning programmes, the main variables identified in this study should be further investigated in different population groups. Addressing men in family planning programmes may improve their success and lead to increased contraceptive use.

Connaissances et attitudes des enseignants de sexe masculin concernant la planification familiale en République islamique d'Iran

RESUME Une étude transversale a été réalisée sur les connaissances et attitudes à l'égard de la planification familiale des enseignants de sexe masculin travaillant dans le système éducatif à Téhéran. Nous avons constaté que $65 \%$ de la population de l'étude avait des connaissances acceptables dans ce domaine. Plus de $95 \%$ des répondants déclaraient avoir une attitude favorable à l'égard de la mise en œuvre des programmes de planification familiale et environ $90 \%$ pensaient que les décisions concernant l'utilisation de contraceptifs devraient être prises en commun. Pour améliorer la planification et l'administration des programmes de planification familiale, les principales variables identifiées dans cette étude devraient faire l'objet d'une étude plus poussée dans différents groupes de population. La prise en compte des hommes dans les programmes de planification familiale peut améliorer le succès de ces programmes et permettre un plus grand recours à la contraception.

${ }^{1}$ Health Education Department, Faculty of Health, Baghyatallah University of Medical Sciences, Tehran, Islamic Republic of Iran.

Received: 24/04/02; accepted: 10/12/02

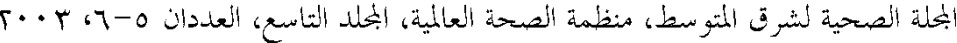




\section{Introduction}

The most important problem of human beings today is not infectious diseases but population. The world population now is higher than at any time in its history. The main problem is the rate of population increase. Statistics show that the population of the world was about 1 billion in 1850 . Eighty years later, in 1930, the population had doubled ( 2 billion). Only 46 years after that, in 1976, it had doubled again [1]. Today, it is more than 6 billion. Increase in population has been deemed the most important socioeconomic and cultural phenomenon in recent decades.

The ramifications of population increase constitute a serious threat; a country with a population greater than its socioeconomic resources can support would be faced with many problems, both cultural and socioeconomic, which in turn would influence its independence.

Examining the population records of our country (Islamic Republic of Iran), it can be seen that over a period of about a century, from 1900 onward, the population increased 6-fold (from 10 million to 60 million). The last doubling of the population occurred over a period of only 20 years, 1979-1999 [2]. This increase in population affects many aspects of society, including living conditions, basic needs, employment status and the health system. Because of the great effect population size has on socioeconomic status, education and health planning, a full understanding of this phenomenon and the major factors governing it is essential.

The results of earlier studies have indicated that in order to have a successful programme in the domain of population control and family planning, beliefs, attitudes, behaviour and the viewpoints of the public regarding reproduction should be taken into account [3]. Practising family planning is influenced by various social, cultural, economic and political factors. Most research into family planning and reproductive health services targets women, particularly ever married women of reproductive age. Consequently, these services, as well as the research, have not addressed a large number of issues concerning men (S. Basnayak, S. Thapa, unpublished report, 1985).

It needs to be recognized that women, particularly in developing economies, are often economically and emotionally dependent on their male partners (G. Gordon, C. Kanstrup, unpublished report, 1995). The need to encourage and enable men to take responsibility for their sexual and reproductive behaviour and their social and family roles was also stressed during the International Conference on Population and Development (Cairo, Egypt, 1994) [4].

The behavioural and psychosocial aspects of reproductive health issues concerning men revolve around their involvement in contraceptive programmes, assuming a greater responsibility for and participation in all matters related to conjugal relations, and promoting a greater understanding of male sexual health problems and their management.

Very few studies have actually looked into men's attitudes about contraception, pregnancy and child rearing or into the possible ways of changing their possible resistance towards family planning, especially to the use of contraception (Population Council, unpublished data, 1994).

A study conducted in Sudan on male viewpoints on the issue of family planning indicated that there is a positive association between male involvement and the success of family planning programmes [5]. Our paper examines knowledge of and attitudes to family planning programmes by Iranian

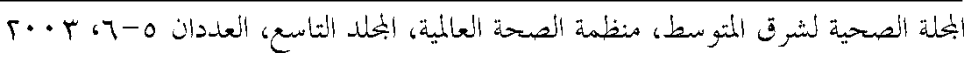


male teachers. Their beliefs about decisionmaking regarding the use of contraceptives are also reported.

\section{Methods}

We carried out a cross-sectional study during May 1998 to investigate knowledge and attitudes of family planning by male teachers working in the different levels of the 19 regions of the education system in Tehran, a total population of 2615 teachers. The sample for the study population was calculated using the formula:

$$
n=\mathrm{z}^{2} p q / d^{2}
$$

where $n$ is the desired sample size, $\mathrm{z}=1.96$ at $95 \%$ significance level, $p=$ is the prevalence of the dependent variable in the community, $q=(1-p), d=$ degree of accuracy.

The number of particpants was 365, randomly drawn from the selected population. The collected data were coded and analysed using SPSS. The chi-squared test was used for statistical analysis.

We designed a questionnaire to assess knowledge and attitude with regard to family planning. This was pre-tested for validity by administering to 20 teachers from the same population, following which 2 questions were removed. To determine the level of knowledge of the respondents, each question received 1 point. The results were then categorized, a score of $\leq 9$ indicating little knowledge, 10-15 moderate knowledge and 16-20 good knowledge.

The attitude of the respondents with regard to family planning was assessed and analysed in a similar way, 1 point being given for each of the 28 questions. Attitude was categorized with a score of $\leq 17$ graded as negative attitude, 18-23 moderately positive and 24-28 positive.

\section{Results}

Age distribution of the participants is shown in Table 1. The mean age was 33.3 years (standard deviation 7.3), 20\% were $\leq 40$ years. The results also showed that $44.4 \%$ of respondents had graduated from high school and $55.6 \%$ had higher education. Most of the information regarding contraceptives was received through television (65.8\%) and radio (50.7\%) (Table 2). Although $69.6 \%$ of participants were familiar with health centres, only $3.8 \%$ mentioned the health centre or physician as a source of information. The best age for marriage was considered to be between the ages of 25 and 29 years for males accord-

Table 1 Distribution of the participants by

age

\begin{tabular}{lcc}
\hline Age (years) & No. $(\boldsymbol{n}=\mathbf{3 6 5})$ & $\%$ \\
\hline $20-29$ & 136 & 37.3 \\
$30-39$ & 156 & 42.7 \\
$40-49$ & 64 & 17.5 \\
$\geq 50$ & 9 & 2.5 \\
\hline
\end{tabular}

Mean $=33.3$ years, standard deviation $=7.25$ years.

Table 2 Distribution of the participants according to source of information regarding family planning

\begin{tabular}{lcc}
\hline Source & No. $(\boldsymbol{n}=\mathbf{3 6 5})$ & \% \\
\hline Television & 240 & 65.8 \\
Radio & 185 & 50.7 \\
Book & 126 & 34.5 \\
Press & 119 & 32.6 \\
Formal education & 67 & 18.4 \\
\hline
\end{tabular}

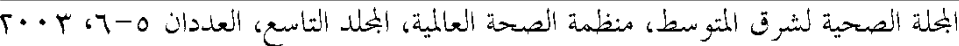


ing to $68.1 \%$ of the respondents, whereas $57.0 \%$ considered the best age for marriage for women to be 20-24 years, with $37.1 \%$ believing $<19$ years was the best age (Table 3).

The best age for pregnancy was considered to be $20-29$ years by $95.9 \%$ of the respondents, $<19$ years by $3.6 \%$ and $30+$ years by $0.5 \%$. For knowledge regarding family planning, $20.2 \%$ of the study sample had a low level of knowledge, while $64.7 \%$ and $15.1 \%$ respectively had scores indicating a moderate or good level of knowledge. A majority of the respondents, $71.0 \%$, had a positive attitude towards family planning programmes, with $25.8 \%$ having a moderately positive attitude and only 3.3\% having a negative attitude. The results also indicated that $88.8 \%$ of respondents believed that decision-making regarding family planning was a joint process. The proportion of respondents who considered that this should be solely a male or female decision was $10.1 \%$ and $1.1 \%$ respectively.

We found $97 \%$ of the 72 unmarried respondents stated that they agreed with the administration of family planning programmes and would practise contraception following marriage. Regarding preferred family size, only $17.8 \%$ of respondents believed that 3 children would be ideal (Table 4). Education status was also investigated in relation to actual family size of the re-

Table 3 Distribution of the 365 participants by beliefs about the best age for marriage for males and females

\begin{tabular}{|c|c|c|c|c|}
\hline \multirow{2}{*}{$\begin{array}{l}\text { Best age } \\
\text { (years) }\end{array}$} & \multicolumn{2}{|c|}{ For males } & \multicolumn{2}{|c|}{ For females } \\
\hline & No. & $\%$ & No. & $\%$ \\
\hline$<19$ years & 9 & 2.5 & 136 & 37.3 \\
\hline 20-24 years & 108 & 29.6 & 208 & 57.0 \\
\hline $25-29$ & 248 & 68.1 & 21 & 5.8 \\
\hline
\end{tabular}

Table 4 Distribution of participants by ideal number of children per family

\begin{tabular}{lrr}
\hline $\begin{array}{l}\text { Ideal number } \\
\text { of children }\end{array}$ & No. $(\boldsymbol{n = 3 6 5 )}$ & $\%$ \\
\hline 1 & 12 & 3.3 \\
2 & 265 & 72.6 \\
3 & 65 & 17.8 \\
$\geq 4$ & 23 & 6.3 \\
\hline
\end{tabular}

spondents, which showed that $55.6 \%$ of the respondents with a high school diploma had 1 or 2 children and 39.4\% had $\geq 3$ children. The results for those with a higher level of education were $61.6 \%$ and $13.9 \%$ respectively (Figure 1).

More than $89 \%$ of the married respondents had married between the ages of 20 and 29 years (Table 5).

To determine the relationship between knowledge of family planning and marital status, a chi-squared test was applied (Ta-

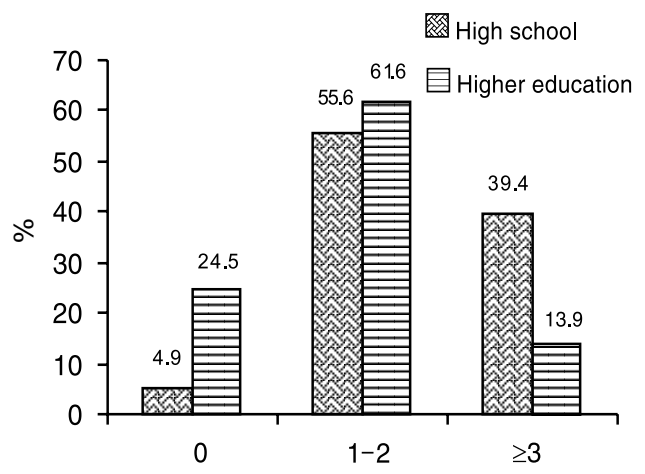

No. of children

Figure 1 Distribution of the married study population by educational status and number of children 
Table 5 Distribution of married participants by age at marriage

\begin{tabular}{lrr}
\hline $\begin{array}{l}\text { Age at marriage } \\
\text { (years) }\end{array}$ & No. $(\boldsymbol{n}=\mathbf{2 9 3})$ & $\%$ \\
\hline$<19$ & 5 & 1.7 \\
$20-29$ & 262 & 89.4 \\
$30-39$ & 25 & 8.5 \\
$\geq 40$ & 1 & 0.3 \\
\hline
\end{tabular}

ble 6). The results show a statistically significant relationship between the 2 variables $(P<0.001)$.

A chi-squared test was used to determine the relationship between awareness of methods of contraception and the education status of the respondents. The results show a statistically significant positive relationship between the 2 variables (Table 7), i.e. higher education status corresponded with increased knowledge of contraceptive methods $(P<0.05)$.

\section{Discussion}

Analysis of the results showed that approximately $80 \%$ of respondents were familiar with family planning programmes. This knowledge was obtained through a variety of means, television being the main source of obtaining information among the study population $(65.8 \%)$, followed by radio (50.7\%) (Table 2). These results are comparable with those of a previous study which reported $45 \%$ and $39.7 \%$ for television and radio respectively, these being considered the 2 most important sources [6]. This indicates that, in the Islamic Republic of Iran, the mass media in general, and television and radio in particular, are the most important sources of information regarding health issues such as family planning. In contrast to our findings, in another Iranian study, the health centre was mentioned by a considerable portion of the respondents $(41.5 \%)$ as their source of information. This was followed by physician $(14 \%)$, friends $(12 \%)$ and books (4.5\%) [7]. In another study, the health centre as a source of obtaining information was reported by $33.6 \%$ [8].

Our study also shows that $69.6 \%$ of the study population were familiar with health centres and family planning clinics, i.e. about $30 \%$ of the teachers are not familiar with these centres. Therefore, in order to run a successful family planning programme in practical terms, we need to promote health centres more.

\begin{tabular}{|c|c|c|c|c|c|c|}
\hline \multirow[t]{3}{*}{ Marital status } & \multicolumn{6}{|c|}{ Knowledge of family planning } \\
\hline & \multicolumn{2}{|c|}{ Little } & \multicolumn{2}{|c|}{ Moderate } & \multicolumn{2}{|c|}{ Good } \\
\hline & No. & $\%$ & No. & $\%$ & No. & $\%$ \\
\hline Unmarried $(n=72)$ & 30 & 41.7 & 34 & 47.2 & 8 & 11.1 \\
\hline Married $(n=293)$ & 44 & 15.0 & 202 & 68.9 & 47 & 16.0 \\
\hline Total & 74 & 20.3 & 236 & 64.7 & 55 & 15.1 \\
\hline
\end{tabular}

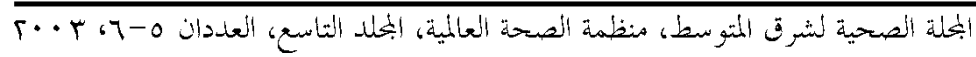




\begin{tabular}{|c|c|c|c|c|c|c|c|c|}
\hline \multirow{2}{*}{$\begin{array}{l}\text { Education status } \\
\text { High school diploma }(n=162)\end{array}$} & \multicolumn{2}{|c|}{$\begin{array}{c}0 \text { methods } \\
\text { No. \% }\end{array}$} & \multicolumn{2}{|c|}{$\begin{array}{c}1-3 \text { methods } \\
\text { No. } \%\end{array}$} & \multicolumn{2}{|c|}{$\begin{array}{c}\text { 4-6 methods } \\
\text { No. \% }\end{array}$} & \multicolumn{2}{|c|}{$\begin{array}{c}\text { 7-8 methods } \\
\text { No. } \%\end{array}$} \\
\hline & 1 & 0.6 & 33 & 20.4 & 114 & 70.4 & 14 & 8.6 \\
\hline Higher education $(n=203)$ & 3 & 1.5 & 34 & 16.7 & 129 & 63.5 & 37 & 18.2 \\
\hline
\end{tabular}

$\chi_{3}^{2}=7.80 \mathrm{P}<0.05$.

Approximately 15\% of the respondents had a good knowledge regarding the issue of family planning. Familiarity with family planning programmes is reported by many other studies [8,9]. Rama Rao et al. for instance, reported that knowledge of family planning was widespread and that all the respondents in their study were aware of at least 1 method of contraception [8].

Almost all our participants had a favourable attitude towards family planning, which is similar to the study done by Rama Rao et al. who reported that the majority (80\%) of their respondents were in favour of family planning [8]. Respondents who had favourable attitudes to family planning cited reasons such as health of the mother or the child, having fewer children and maintaining one's standard of living.

Most of our respondents (88.8\%) indicated that decision-making regarding family planning and the use of contraceptives should be a joint process between husband and wife. The important point here is that the respondents did not believe that the decision should be made by the only man or only the woman. A male-based study done in Nigeria indicated that $88 \%$ of males and $78 \%$ of females believed that decisionmaking regarding family planning is more influenced by males (N. Orobaton, unpublished report, 1993). In another study done by Obionu in Nigeria most of the study population had positive attitudes regarding the use of contraceptives [9].

In our study, $76.9 \%$ of all the participants thought that 1-2 children was the ideal family size, which is similar to other studies [10]. Among the married participants, a statistically significant negative relationship was found between number of children and education status. Only $13.9 \%$ of respondents with a higher education had $\geq 3$ children. The majority (61.6\%) had 1-2 children. On the other hand, $39.4 \%$ of married respondents with high school diploma had $\geq 3$ children. The difference between these 2 groups in having 0 children was also quite marked, $4.9 \%$ for those with a high school diploma as opposed to $24.5 \%$ for those with higher education. The results also show a significant correlation between level of education and having information regarding contraceptive methods.

As a result of these associations, one may conclude that formal education plays an important role in many issues related to family planning programmes, such as knowledge of contraception, age of mother at childbirth and number of children. Therefore, this should be taken into account in planning and running family planning programmes in the Islamic Republic of Iran.

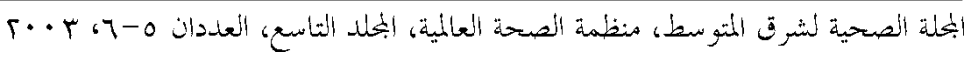


To gain a better understanding of the factors influencing the planning and running of family planning programmes, more studies should be conducted in other population groups with the focus on the main variables identified in this study.

In general, the study reveals good knowledge and understanding of and favourable attitudes towards family planning by male teachers. We suggest that the inclusion of men in family planning programmes would result in an improvement in the success of those programmes and an increase in contraceptive use by married couples.

\section{References}

1. Ministry of Health and Medical Education. Population and family planning programmes in Iran. Teheran, 1995.

2. Shahriary S, Andalib P. Population and family planning. Pezeshky emrouz [Today's medicine], 1998, 241:7.

3. Report of the international conference on population and development, ICPD 94, Cairo, 1994. New York, United Nations Development Programme, 1995 (Report No. A/CONF.171/13).

4. Review and appraisal for the world population plan of action, 1994 report. New York, United Nations, 1995.

5. Khalifa MA. Attitudes of urban Sudanese men toward family planning. Studies in family planning, 1998, 19(4):236 -43.

6. Deldar MH. The survey of knowledge and beliefs of female labourers working in Daroo-pakhsh company in compari- son to those of males [Msc thesis]. Tehran, University of Teheran, 1992.

7. Shafiei M.R. Knowledge, attitude and practice of family planning by married males. [MSc thesis]. Tehran, Islamic Republic of Iran, University of Tehran, 1997.

8. Rama Rao GR, Moulasha K, Sureender S. Knowledge, attitude and practice of family planning among fishermen in Tamil Nadu. Journal of family welfare, 1993, 39(3):50-54.

9. Obionu CN. Family planning knowledge, attitude and practice amongst males in a Nigerian population. East African medical journal, 1998, 75(3):131-4.

10 Akin A, Rahar S. Final report on operation research for an effective information and education approach for family planning Ankara. Ankara, Hacettepe University, 1991.

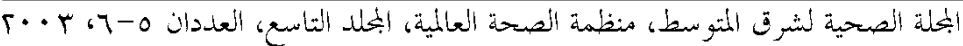

